\title{
CALAS EN LA LITERATURA ESPAÑOLA DEL SIGLO DE ORO
}

\author{
José Romera Castillo
}

(Madrid: Universidad Nacional de Educación a Distancia, 1998, 536 págs.)

Hoy en día se utiliza la expresión «Siglo de Oro» para referirse al período de mayor florecimiento cultural en la España hegemónica. Es la época en la que escribieron Garcilaso, Fray Luis de León, Herrera, San Juan de la Cruz, Cervantes, Lope de Vega, Calderón, Góngora y Quevedo. El predominio de todos los géneros mayores durante este período es la causa de que, cuando decimos «Siglo de Oro» tengamos que pensar tanto en el siglo XVI como en el XVII. Calas en la literatura española del Siglo de Oro abarca cronológicamente temas y autores relacionados con ambos siglos.

Los estudios que forman parte de este volumen son el fruto de los años de investigación y docencia que el profesor José Romera Castillo ha dedicado al período áureo de nuestra literatura. Los diferentes capítulos que integran el libro son recopilación de trabajos de investigación publicados originariamente en revistas y actas de congresos nacionales e internacionales. Esta recopilación rinde homenaje a Dámaso Alonso 
en el centenario de su nacimiento y a Emilio Alarcos Llorach con motivo de su muerte. El volumen es, además, complemento de aquel que el mismo autor publicó, titulado Frutos del mejor árbol. Estudios sobre teatro español del Siglo de Oro (Madrid: UNED, 1993).

Los géneros estudiados abarcan la poesía (Acuña, Quevedo, justas poéticas y el soneto dialogado), el teatro (Calderón, Lope de Vega), la biografía (Cetina), la prosa novelada (Cervantes, Timoneda), la crónica (Colón) y la erudición lingüística (Argote de Molina y Covarrubias). En cuanto a la teoría, el volumen hace gala de un «eclecticismo, no dogmático, que tiende a ser conciliador» (p. 12). Efectivamente, nos encontramos con varios enfoques críticos que siempre resultan adecuados al tema seleccionado.

Cabe ahora hacer un breve resumen de cada uno de los capítulos que, para mayor concisión, he agrupado en diferentes bloques siguiendo criterios estrictamente metodológicos. La comparación literaria es el eje que vertebra varios capítulos. En el primero de ellos se hace una comparación entre la lira de Garcilaso «A la flor de Gnido» y la parodia que de este poema realizó Hernando de Acuña. Sus motivaciones poéticas son bien diferentes, pero las similitudes formales y métricas son numerosas; lo que demuestra que Acuña, en realidad, está rindiendo homenaje a Garcilaso. El tema sobre la recepción literaria, tan fructífero en literatura comparada, da lugar al capítulo titulado «Algo más sobre Gutierre de Cetina y México». Hasta ahora sólo se conocía un cancionero manuscrito de Cetina recopilado en la ciudad de México en 1577. La aportación de Romera Castillo consiste en dar a conocer otro manuscrito mexicano que ratifica la huella del poeta en las tierras de Nueva España. Dentro de esta misma línea comparativa se encuentra la investigación dedicada a Lope de Vega. Existe una similitud temática, de origen boccacciana, en El ejemplo de casadas, de Lope de Vega, y en la segunda patraña de Timoneda. El tema, recurrente en nuestra literatura culta y popular, es la historia de la fidelidad conyugal de la mujer. El amplio capítulo dedicado a Joan Timoneda cabe también en su mayor parte dentro de otro gran apartado de la comparación literaria dedicado a la búsqueda de ecos, concomitancias e influencias. Romera Castillo analiza las huellas que ha dejado el medievo en la colección de relatos agrupados en El patrañuelo, la obra literaria cumbre de la narrativa de Joan Timoneda. Después, analiza las concomitancias temáticas entre obras cervantinas (por ejemplo, La Galatea y La gitanilla) y el texto de Timoneda. Por último, se coteja la patraña segunda de Timoneda y la Historia de Valter e Griselda, de Bernat Metge. 
Varios son también los capítulos que se agrupan en torno al eje metodológico del análisis lingüístico. El capítulo sobre «Argote de Molina» está dedicado a la reflexión lingüística que el sevillano realizó sobre El Conde Lucanor. Su pormenorizado análisis sobre el estado de la lengua en el siglo XVI lo ubican dentro de aquellos humanistas -Nebrija, «El Brocense» y Covarrubias- que asientan los fundamentos de la ciencia lingüística posterior. Ese mismo enfoque lingüístico es también el eje vertebrador del capítulo dedicado a las autoridades medievales que Sebastián de Covarrubias utilizó en su Tesoro de la lengua castellana o española con el objetivo de documentar definiciones. Los escritores y las obras que aparecen explícitamente en el Tesoro, prescindiendo de romances y composiciones populares son Juan de Mena, Coplas de Mingo Revulgo, La Celestina, Pero López de Ayala, Juan del Encina, El Conde Lucanor. En otro capítulo José Romera Castillo desglosa un soneto de Hernando de Acuña para ratificar que se ajusta a las categorías funcionales del soneto amoroso clásico. Dentro del plano estrictamente lexicográfico, hay que destacar el capítulo dedicado a Quevedo, en el que se analizan los campos léxicos de su frondosa obra poética para demostrar el funcionamiento conceptual del binomio tiempo-muerte.

Los problemas de datación y autoría inspiran la investigación dedicada a Calderón de la Barca. Bajo el epígrafe «Notas sobre Casa con dos puertas, mala es de guardar y El galán fantasma» se analiza la datación, el género, el argumento, los personajes, el estilo y la métrica de estas dos obras. Después, se apuntan los preliminares que ha de seguir la crítica literaria para la edición del auto sacramental La cruz donde murió Cristo. Este auto es cotejado con La exaltación de la Cruz, teniendo como punto de referencia los personajes, los espacios escénicos, los temas, los recursos técnicos y teatrales, y el léxico. Los problemas de autoría dan lugar a un nuevo apartado dentro del teatro calderoniano. A través del análisis de una serie de antítesis y contrastes, José Romera Castillo demuestra que la obra No hay que creer ni en la verdad fue, efectivamente, escrita por Calderón de la Barca.

Originales resultan los planteamientos críticos utilizados para analizar la obra de otros dos autores: Cervantes y Colón. En el primer caso se utiliza el psicoanálisis -y, más concretamente, el «triángulo edípico»- para desvelar el mundo interno del autor del Quijote. No menos llamativa es la interpretación kinésica que se hace del Diario del descubrimiento, de Cristóbal Colón. La comunicación no verbal, a través de movimientos y posiciones corporales de base psicomuscular, de 
percepción visual, acústica, táctil y cinestésica, fue la primera forma de contacto entre dos culturas antagónicas que lograron entablar diálogo con gestos.

No menos interesante resulta el capítulo dedicado a Teresa de Jesús en el que se analiza la presencia de justas poéticas y representaciones literarias durante la celebración de fiestas teresianas en honor a la beatificación de la Santa. En estos certámenes, y siguiendo las fuentes de la época, participaron poetas de renombre: Lope de Vega, Miguel de Cervantes, José de Valdivielso, Gaspar Aguilar, Vicente Espinel... Las justas se celebraron por toda la geografía española. Sobre las de Córdoba y Valencia se dedica un pormenorizado estudio.

Cabe decir, para concluir, que los trabajos publicados en Calas en la literatura española del Siglo de Oro están ordenados alfabéticamente (por autores), lo que constituye una decisión acertada para ayudar al lector a servirse con agilidad de la variada información. Todos los capítulos destacan por el manejo de abundantes fuentes bibliográficas, tanto primarias como secundarias, y por el deseo de indagar en aspectos de nuestra literatura que requieren aún una pormenorizada investigación.

Dolores Romero López Grupo de Investigación del ISLTYNT de la UNED 